\title{
Queue-based quantitative approach for border guard operational modelling. Constructive simulator models reflecting border crossings and blockade elements.
}

\author{
Mariusz Chmielewski ${ }^{1, \mathrm{a}}$, Marcin Kukietka ${ }^{1, \mathrm{~b}}$ \\ ${ }^{1}$ Military University of Technology, Cybernetics Faculty, gen. W. Urbanowicz Street 2, Warsaw, Poland
}

\begin{abstract}
The paper presents selected modelling techniques utilised in constructive simulation environment SymSG Border Tactics which provides tactical training capabilities for Polish Border Guard. Operational responsibilities of BG include policing as well as reconnaissance, transport and traffic control in near border areas. Modelling of such operations require multiresolution approach, as many of operational elements can be modelled as aggregated entities but majority of active simulation elements need to be implemented as individual simulation objects. The behavioural models reflecting BG, perpetrators or society have been modelled as agents and more complex operational elements (e.g. road blockades, control points during temporary restoration of the border control, border crossing) are modelled using queue system. Such approach delivers flexibility of system modelling but most of all is tuned to the calibration parameters provided by the BG analysts. Therefore, developed modelling approach provides flexibility in customisation of the model (simulation element) based on the user and scenario preferences. Constructive simulator has been designed to support brief (up to $4 \mathrm{~h}$ ) live exercises and reflect training of border guard outpost operational tasks. Finally the paper describes architectural solutions developed to support modelling approaches and required functionalities for simulation execution, after-action-review mechanism and remote simulation access.
\end{abstract}

\section{Introduction motivation}

and

research

SymSG Border Tactics is composed of two simulation environments, which provide constructive and virtual types of simulation. The need for constructing two separate simulation modules, comes from separate operational requirements. The constructive simulator supports command level decision making, performed in map module and SWK imitator (real command support system) used by border guard. The constructive module operates mainly on map view and requires from trainee implementation of decisions in form of tactical symbology [1],[3]. Constructive simulator [10],[11] supports major operational tasks connected with: border patrolling, disclosure of smuggling, blocking and pursuit operations, road checkpoints, border crossing control. The simulator contains models reflecting active elements of border guard, police, military, perpetrators and community within given urban areas. The models have been developed according to behavioural models codified in border guard service guidelines. Command Post Constructive Simulator therefore requires operational elements acting as aggregated entities having internal, configurable and adjustable structure. The purpose of this research is to analyse the required behaviour of blockades, check points and border crossings, identify required features and propose measures defining operational processes. The simulator needs to deliver construction of these models during execution of the exercises and calibration of the models during scenario construction. Utilised operational elements features, needed to be verified by $\mathrm{BG}$ experts in order to acknowledge their realisms and possibility to calculate them based on real world data gathered from BG decision support tools.

The main motivation for the paper is to present novel approach for modelling simulation entities reflecting stationary or temporal operational elements with complex internal structure and behaviour. Elaborated approach supports addition generation of internal events affecting the efficiency of executed elements' behaviours. Finally, we present implementation insights and map module creator application which supports configuration and monitoring of active elements (blockages, check points, border crossings).

\section{SymSG simulator environment}

The main objective of the project is to develop a multiresolution simulation environment for conducting simulation exercises (including simulation verification of procedures and decisions taken by the managers of the Polish Border Guard). SymSG Border Tactics provides a comprehensive approach to training needs defined by the

\footnotetext{
${ }^{a}$ Mariusz Chmielewski: mchmielewski@wat.edu.pl

b Marcin Kukiełka: marcin.kukielka@,wat.edu.pl
} 
Border Guard Training Centre. The developing environment will offer support to the process of training shift managers and officers practicing as Operation Commanders - action managers. Parallel to the preparation of the simulation system, training center (CSSG) works are aimed at adjusting training programmes for Border Guard officers and managers, in which the simulation environment is used according to proposed CAX (Computer Assisted Exercises) methodology.

Border Guard tactical training environment consisting of:

- Command Post Constructive Simulator [CPCS] -Map Module + Simulation Engine + SWK C2 application + Communication module -IX TRL;

- High-Detail Virtual Simulator [HDVS] (virtual simulator based on VBS3 solution) -3 functional scenarios -IX TRL;

- Elaborated and implemented Border Guard and supporting services behavioural models delivered as components for CPCS;

- Elaborated and implemented models of objects, equipment, weapons, vehicles, infrastructure delivered as components of HDVS;

- Utility tools for assessing simulation exercises and evaluating the efficiency of trainees - supplemented with After-Action-Review capabilities AAR;

- CAX Methodology - computer assisted exercises guidelines for simulation environment utilisation in BG training and procedures research;

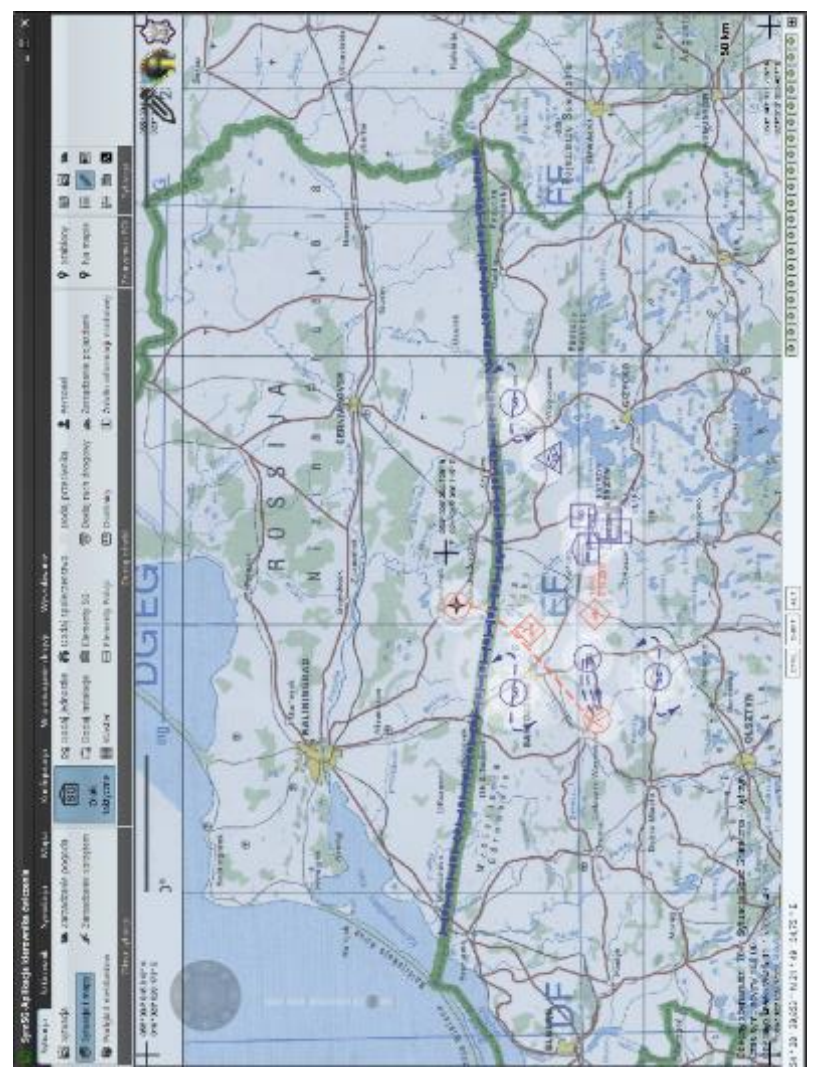

Fig. 1. Command Post Constructive Simulator [CPCS] view operating a simulation scenario in NE Poland involving forceful crossing of border followed by recognised terrorist threat
In order to support integration features an ESB (Enterprise Service Bus) integration environment has been adopted providing communication mechanisms and synchronisation of simulation system components. Additionally, HLA RTI environment has been provided and configured for possible future integration with external simulators interacting in joined CAX. The main task of the integration environment is to provide access to the synchronous and asynchronous communication infrastructure in the simulation environment in order to unify integration standards within the simulation environment (integration of environment components) on the one hand and to provide mechanisms for integration of external simulation tools and IT systems, including other simulation systems.

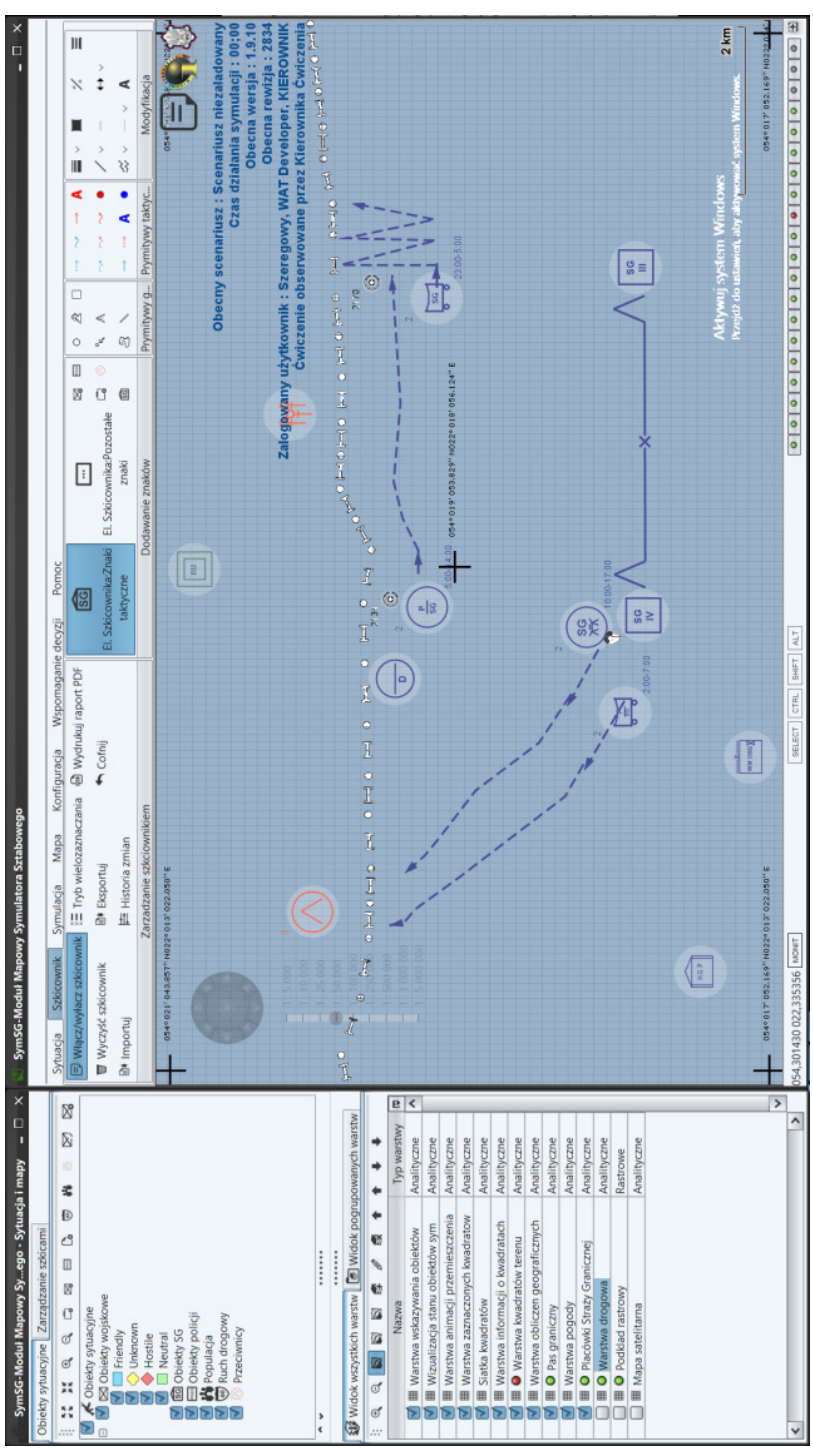

Fig. 2. Example simulation scenario implementation in Command Post Constructive Simulator [CPCS]. View contains scenario with constructed border crossing, supplemented with patrolling-pursuit operation

The simulation environment consists of set of initial 10 simulation scenarios (various size and time spectrum) approved by the experts and prepared based on the hypothetical episodes. The scenarios, reflect training 
needs at the level of the Shift Commanders and the Operation Coordinators.

The proposed simulation system solution is aimed at the integration of other simulation systems (police force, military combat simulator) reporting, decision support and communication applications. The innovation of applied integration approach is to provide interoperability capabilities for the environment do utilise external tools as interaction or event generators, operational picture viewers or data editors.

The main objective of the project is to build novel, innovative tools (such as simulation environments) with tailored methodology for conducting CAX exercises delivering new means for efficient training. The project is a pioneer in providing a simulation system that integrates with main tool for managing border guard activities and registered events.

\section{Model Requirements}

The Polish Border Guard operations are mostly conducted in synchronized, sequenced patterns. A vehicle approaching border crossing need to wait for his turn to be serviced by Border Guard Officer and then by analogy wait for being processed by Customs Officer. Blockade elements work in similar manner. While driver is approaching blockade he can be spotted by observation point and then assigned to be stopped by the checkpoint. When the Border Guard Officers are busy controlling other vehicles the driver need to wait for his turn.

The main difference is that the border crossing is a static element, while blockade can be conducted dynamically on purpose. Patrol or a task group can be used, as a base for preparing the blockade elements including observation and controlling posts, blockade itself and for isolating a pursuit squad. This effects in the necessity of consideration of task group as a separate simulation agent. There are some possibilities that need to be considered while designing the operational element, e. g. the driver's escape or attempt to forcedly exceed border.

A number of these activities can be described as a FIFO (first-in-first-out) queues. This approach represents the real queue of travellers. The extraordinary, uncommon events like fire alarm or force exceeding border need to be treated in different manner as they change the standard flow of service by invoking specialized handling procedures. Elements of significant grouping are modelled as an aggregate.

The basis of action either of border crossing and blockade is traffic. The traffic is generated from nearby cities which must be set by the script writer during preparation of simulation scenario. These generators are the main determinant of intensity of input flow $\lambda_{1}$.

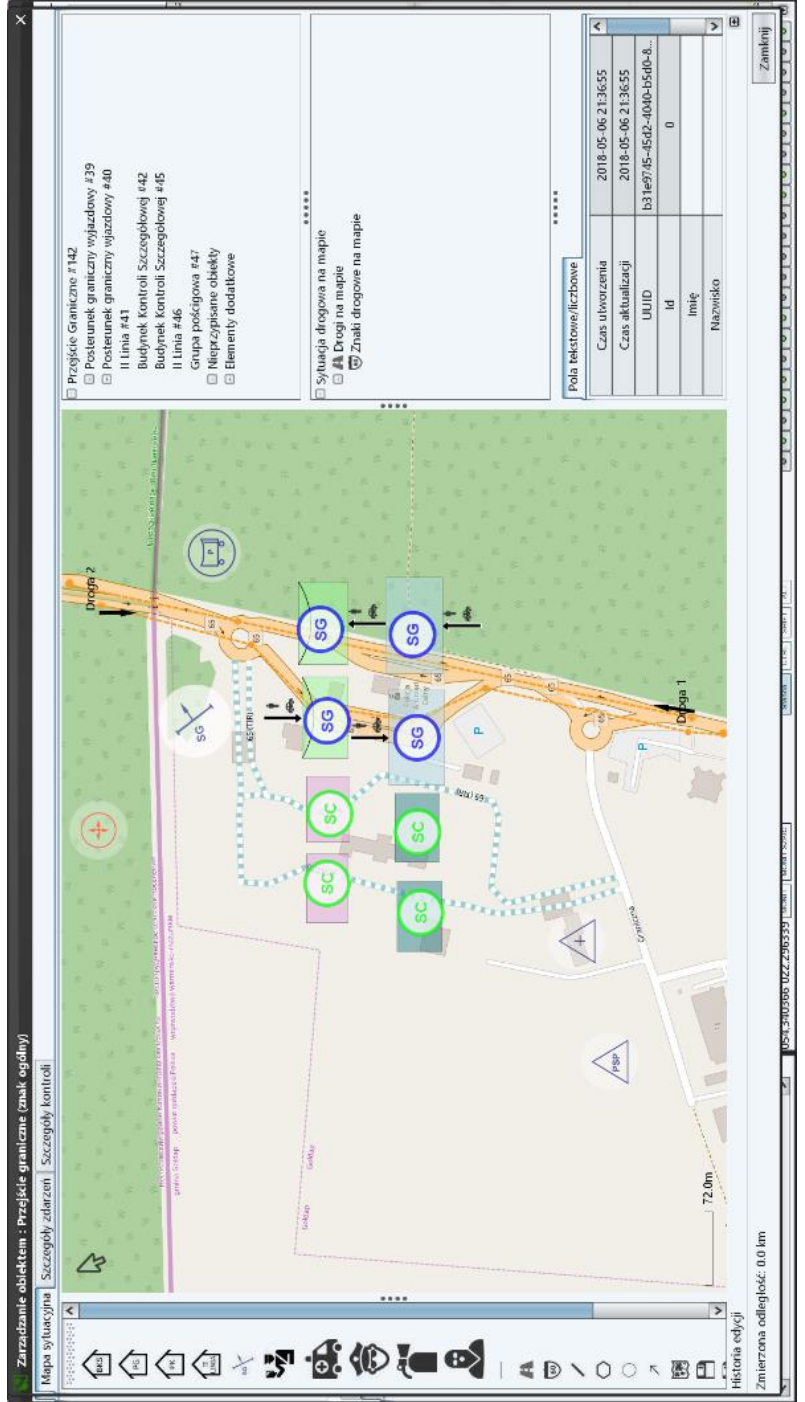

Fig. 3. Designed and implemented border crossing operational element in SymSG simulation environment containing definitions of all functional elements with configuration capabilities

\section{Formal simulation model}

In order to enhance the capabilities of queue-based approach, some quantitative parameters were introduced. The queues were designed as an entry point to simulation model so that each traffic object will be processed.

Based on the border crossing structure, some points of service can be determined: entry gate, border guard control and customs control. Each post also has queues as an entry point what reflects real situation at border crossing as depicted on Fig. 3. 


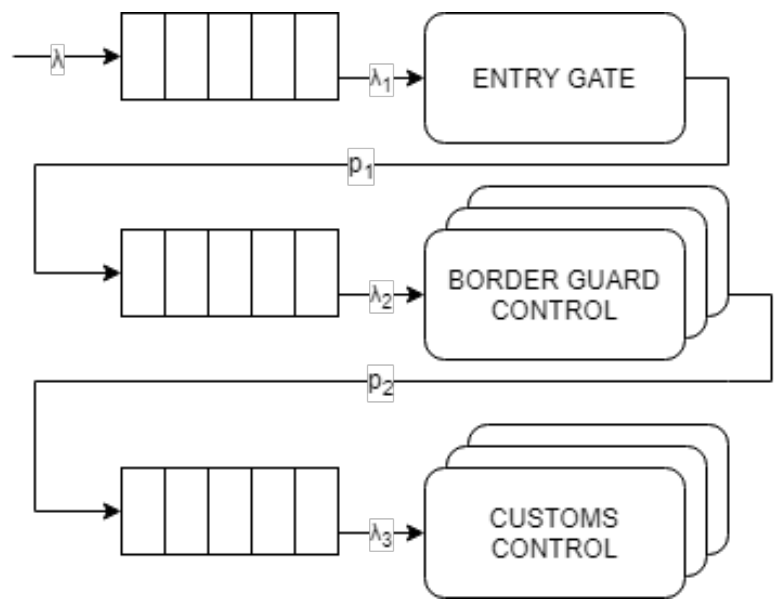

Fig. 4. Border crossing simulation flow

Presented diagram reflects standard flow of simulation when no special events occurred. The $\lambda$ and $\lambda_{\mathrm{i}}$ symbols describe the intensity of inflow to significant queue while $\mathrm{p}_{\mathrm{j}}$ parameters are probabilities of passing to following service slot. In order to provide more accurate model some optional elements were designed, e. g. second line or detailed control point as pictured (Fig. 5).

Table 1. Operational symbology and elements utilised in element descriptions (blockade, border crossings)

\begin{tabular}{|c|c|}
\hline $\begin{array}{c}\text { Icon - operational } \\
\text { symbol }\end{array}$ & $\begin{array}{l}\text { Description } \\
\text { Operational element }\end{array}$ \\
\hline & $\begin{array}{l}\text { Observation and } \\
\text { registration post }\end{array}$ \\
\hline & $\begin{array}{c}\text { Control post } \\
\text { (team of controllers) }\end{array}$ \\
\hline & $\begin{array}{c}\text { Blockade } \\
\text { operational element } \\
\text { (group) }\end{array}$ \\
\hline & Pursuit team \\
\hline & $\begin{array}{l}\text { Border Guard } \\
\quad \text { officer }\end{array}$ \\
\hline$\notin 88$ & $\begin{array}{l}\text { Road spike strip } \\
\text { (road spikes) }\end{array}$ \\
\hline- & Perpetrator \\
\hline
\end{tabular}

The entry gate buffer is unlimited in terms of capacity while the capacity of queues before border guard and customs control points can be configured using SymSG environment.

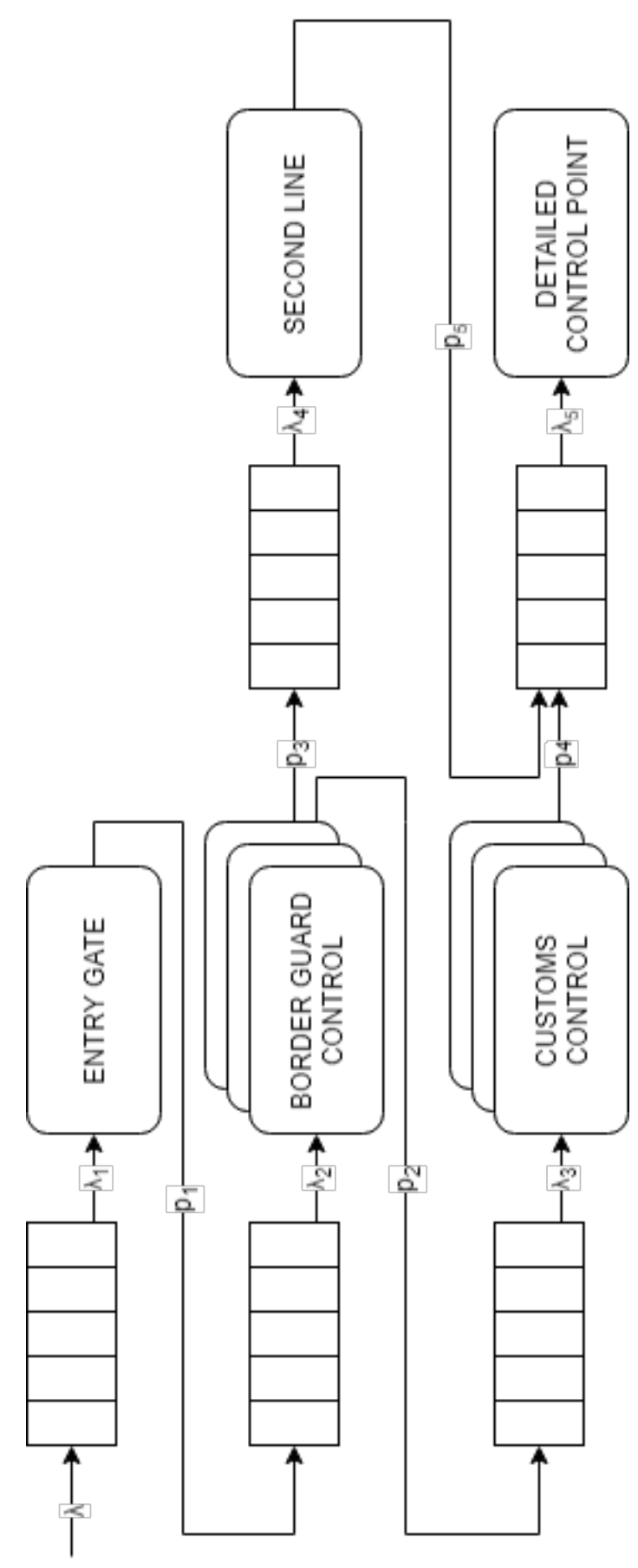

Fig. 5. Border crossing simulation model behavioural flow supplemented by the crossing (optional) check points operational elements (with configuration elements)

Similar approach has been applied for blockade elements modelling. There are several points of service discovered: observation post, controlling post, blockade and pursuit squad. Each of them can be described as queue-based element as seen on Fig.4.-Fig.6. Such approach allows also to handle uncommon events which can escape the whole flow or even be processed in parallel.

The queues in blockade simulation model are designed with unlimited capacity in order to ensure that each event will be processed and each traffic object will 
need to be serviced. The main advantage of queue-based approach is the flexibility of modelling, ease at extension and no restrictions in application of additional methods to support custom events handling. The border crossing simulation model implements several non-standard actions. Basing on probability factors traffic objects can carry prohibited subjects including weapons, explosives, drugs etc.

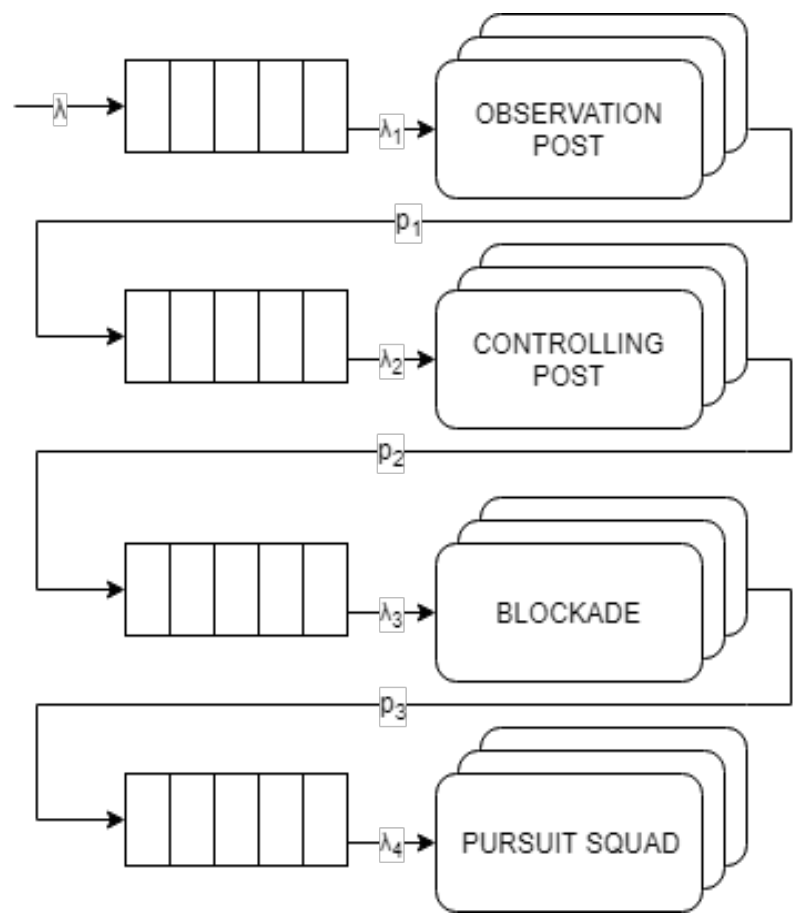

Fig. 6. Blockade simulation model behavioural flow

Another significant functionality is that the model supports simulation of refugees and people smuggling including their aggressiveness and determination factors. When the border guard officer suspects some of these issues he forwards the traveller to second line which depending on type of abuse can process the event itself or pass it detailed control point.

The blockade elements simulation model is capable of supporting unusual events like fire alarms or luggage lost. However, one of the most important flow contains an escape trial. It can be conducted before each of the blockade elements. The traveller can event start to run away in the moment he sees the observation point which is rare because of the camouflage of observation post officers. Most common flee trials are taken during the control.

The model support different behaviours of travellers decisions including forced passing the blockade or turning back before obstacle. In case the suspect somehow passes one of these elements, the pursuit squad is tasked to intercept and catch the opponent. The user of the simulation environment need to take care of logistic supplies including fuel or vehicle assignment to significant elements.

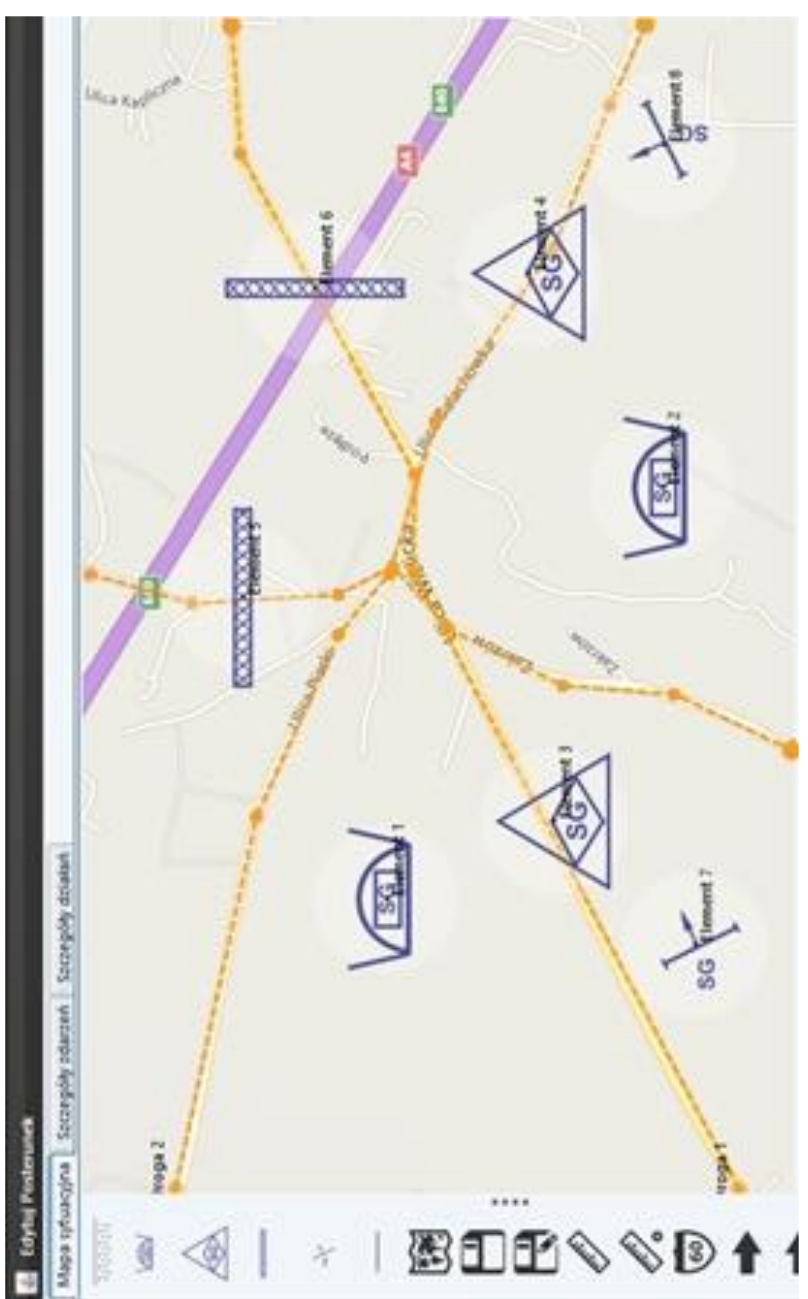

Fig. 7. Blockade elements overview in SymSG environment

\section{Model implementation}

Presented ideas were implemented in SymSG constructive simulation environment using Java programming language utilising DisSim event-driven simulation engine (and its requirements).

In order to provide efficient processing the eventdriven simulation design pattern was introduced. DisSim environment besides events provides also wrappers called action and process. Action is a composition of two events - one at start and one in the end of processing. Process reflects repetition of same events in unit of time. Presented listings show the complexity of simulation models. 


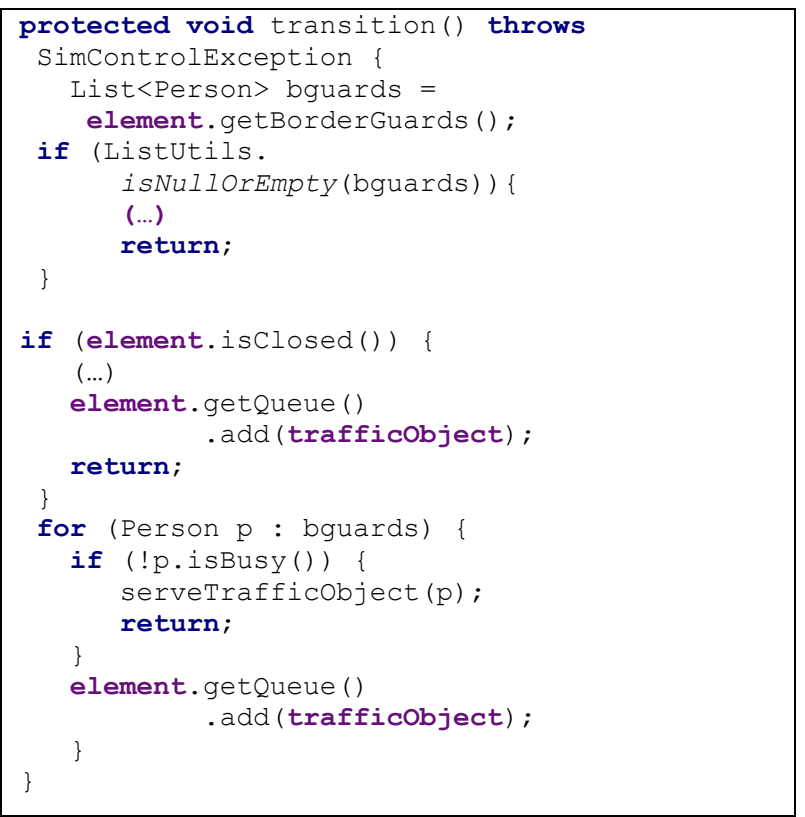

Lis. 1. Implementation of transition method of Border Guards control station in border crossing

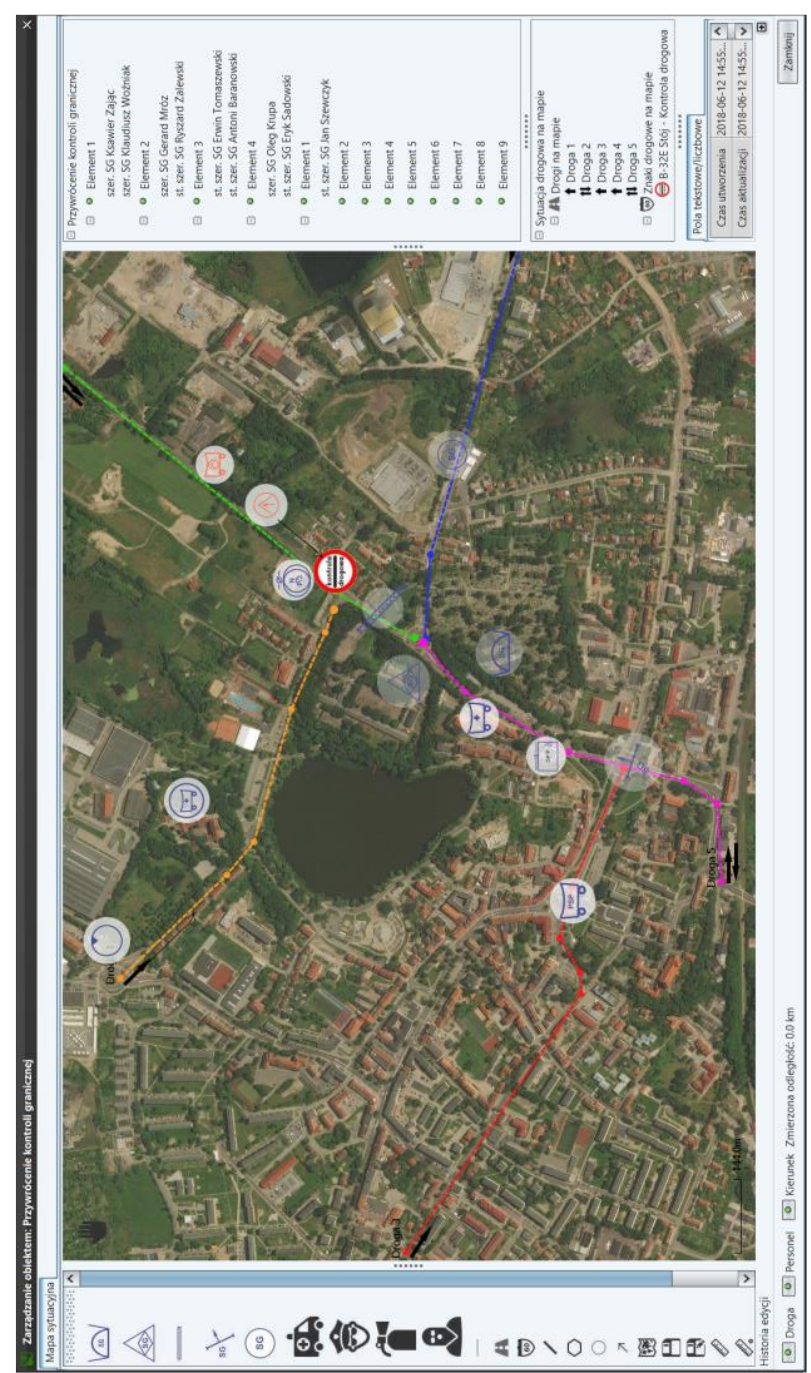

Fig. 8. Road blockade implementation serving as temporary border control element (containing active simulation elements)

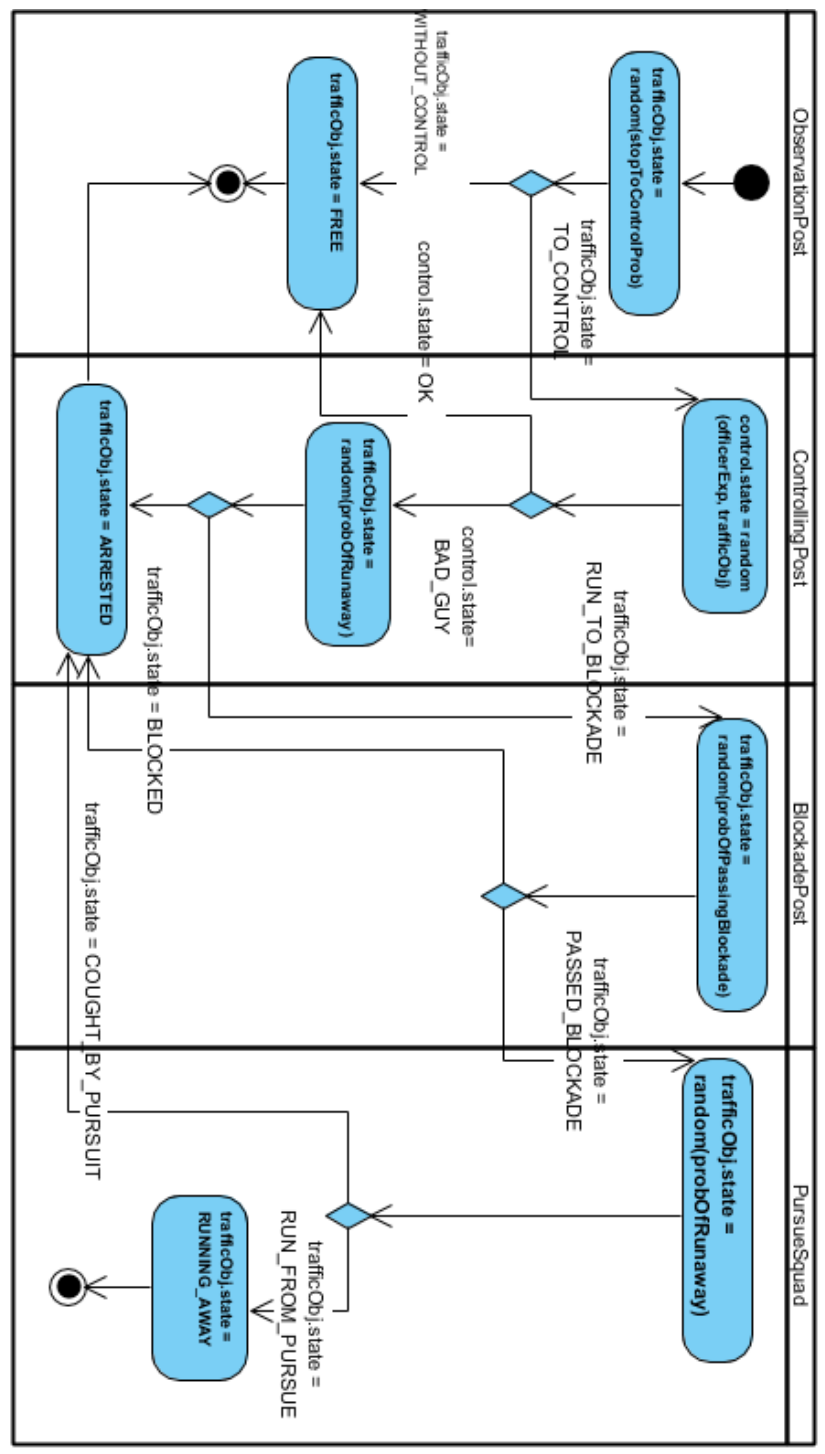

Fig. 9. Road blockade behavioural simulation model - behaviour of BG operational elements (groups of officers or individual actors) acting as active model nodes

Lis. 1 depicts the idea of pushing traffic objects to queue when there are no capabilities of serving. Whereas Lis. 2 addresses the problem of controlling simulation flow by sending significant events. Border crossing as well as blockade elements were implemented mostly using Action objects in order to maintain high flexibility and readability of the proposed solution. Queues were implemented using LinkedList to improve performance of removal and addition of elements. The improvement of insertion time in comparison to ArrayList implementation was estimated to about $22 \%$ while adding to existing list 100 new objects. Conducted efficiency tests show, that LinkedList performs more efficiently in terms of memory usage, especially while removing elements. The GarbageCollector mechanism is not able to shrink the ArrayList empty areas. There was made an approach to setup initial ArrayList capacity to 1024 in order to avoid array expansion. It improved the time of insertion in first 
period of simulation but it caused higher memory usage because it is impossible to assess the required capacity not knowing the exact amount of traffic generator nests and their efficiency.

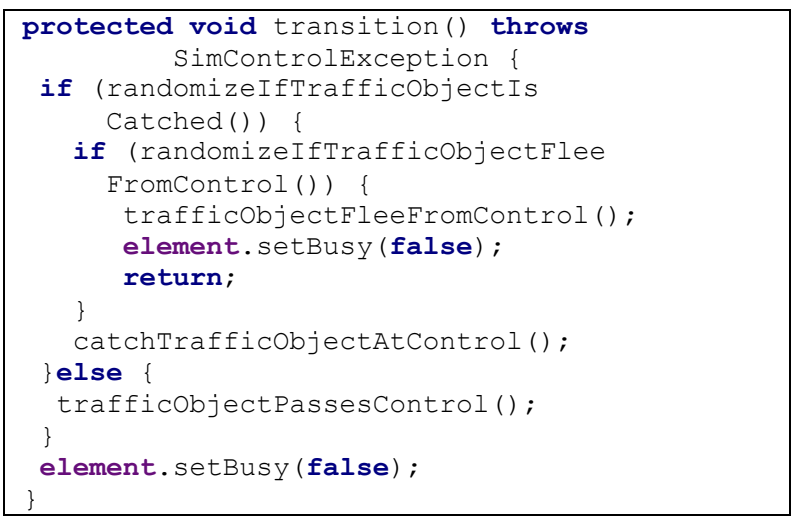

Lis. 2. Implementation of transition method of Controlling Post Officer within blockade operational element

\section{Evaluation environment}

The architecture of developed software combines three main elements: a constructive simulator, a high-resolution simulator (virtual simulator) and an integration environment with support toolkit. Depicted simulation environment contains two modules: a constructive simulator which represents central component of the system aimed at training the Shift Supervisors and high-resolution (virtual) simulator which enhance the capabilities of exercise course of the officers responsible for command operations. The constructive simulator integrates with SWK platform which is widely used software within Polish Border Guard. The high-resolution simulator contains prepared border crossing area Gołdap including detailed modelled roads, rails and Modlin airports located near the town of Gołdap.

The environment enhances support of simulation system operators by application of additional tools:

- Trainee application imitating SWK system. It provides interfaces and operational visualization of activities in the simulator and additional map module which emphasise simulation scenario with forces, objects and resources visualization;

- Exercise supervisor application which serves as manager of the whole simulation exercise. It monitors the students' activity by video streaming, analyse the results and is capable of reproducing the exercise by utilization of After Action Review (AAR) functionality. Application allows also to preview and interact with the training environment utilizing both a podcasting service and monitoring the course of the exercise;

- Scenario planning application which enables the exercise supervisor to create simulation scenarios and geospatial terrain models. It also supports parameterization of simulation scenarios, etc.

- Digital terrain modelling tools designed both for constructive and high-resolution simulator. It allows to construct discrete terrain models and enables integration with map data sets including Shape format, VPF, DTED, ETOPO, CADRG, GeoTIFF, and other open source geospatial information sources like e.g. OpenStreetMap.

The system includes also Behavioural Modelling Environment which simplifies developing algorithms for Border Guard simulation objects, collaborating agencies, perpetrators and criminals. It provides a set of functionalities which allows flexible creation and modification of the simulation logic of the agents what enhances the expansibility of the solution.

Integration within whole system is conducted by Enterprise Service Bus (ESB) which establish simulation system communication and synchronization components. It provides an infrastructure which is capable of service of synchronous and asynchronous communication in a simulated environment. It is used to unify integration standards within the simulator environment components. It also facilitates mechanisms integrating external simulation tools and other heterogeneous data sources. The integration layer based on Runtime Infrastructure (RTI) provides the High Level Architecture simulation standard. RTI provides a flexible, configurable and extensible integration environment for software components and simulators. In order to improve the integration capabilities the layer utilizes external heterogeneous data sources to enable communication with other simulation systems and allow to cooperate with command support tools such as simulators of the Polish Armed Forces (e.g. C2 systems), Police and Fire Brigades.

\section{Evaluation examples}

Constructed models have been evaluated in order to estimate the adequacy of presented algorithms and to verify whether queue-based approach provides required configuration capabilities. The first stage of tests involved constructing prepared variants of BG structures: road blockades, check points and border crossings. The second stage of tests verified the adequacy of models that is evaluation of The evaluation has been conducted using SymSG environment in aspect of creating and modelling border crossing and blockade elements.

Table 2. Evaluation results of border crossing simulation

\begin{tabular}{|c|c|c|}
\hline Element & $\begin{array}{c}\text { Average } \\
\text { time of } \\
\text { service }[\mathbf{s}]\end{array}$ & $\begin{array}{c}\text { Average traffic } \\
\text { serviced }\end{array}$ \\
\hline Entry gate & 10 & 180,00 \\
\hline Border guard control & 313 & 5,75 \\
\hline Customs control & 132 & 13,64 \\
\hline Second line & 488 & 3,69 \\
\hline Detailed control point & 1184 & 1,52 \\
\hline
\end{tabular}


In order to achieve more reliable results all the tests were made on the same machine in similar conditions. There are a few factors that were measured: average time of traffic objects generation, average time of service in each nest of measuring object and probabilities of changing significant logic flow between simulation actors.

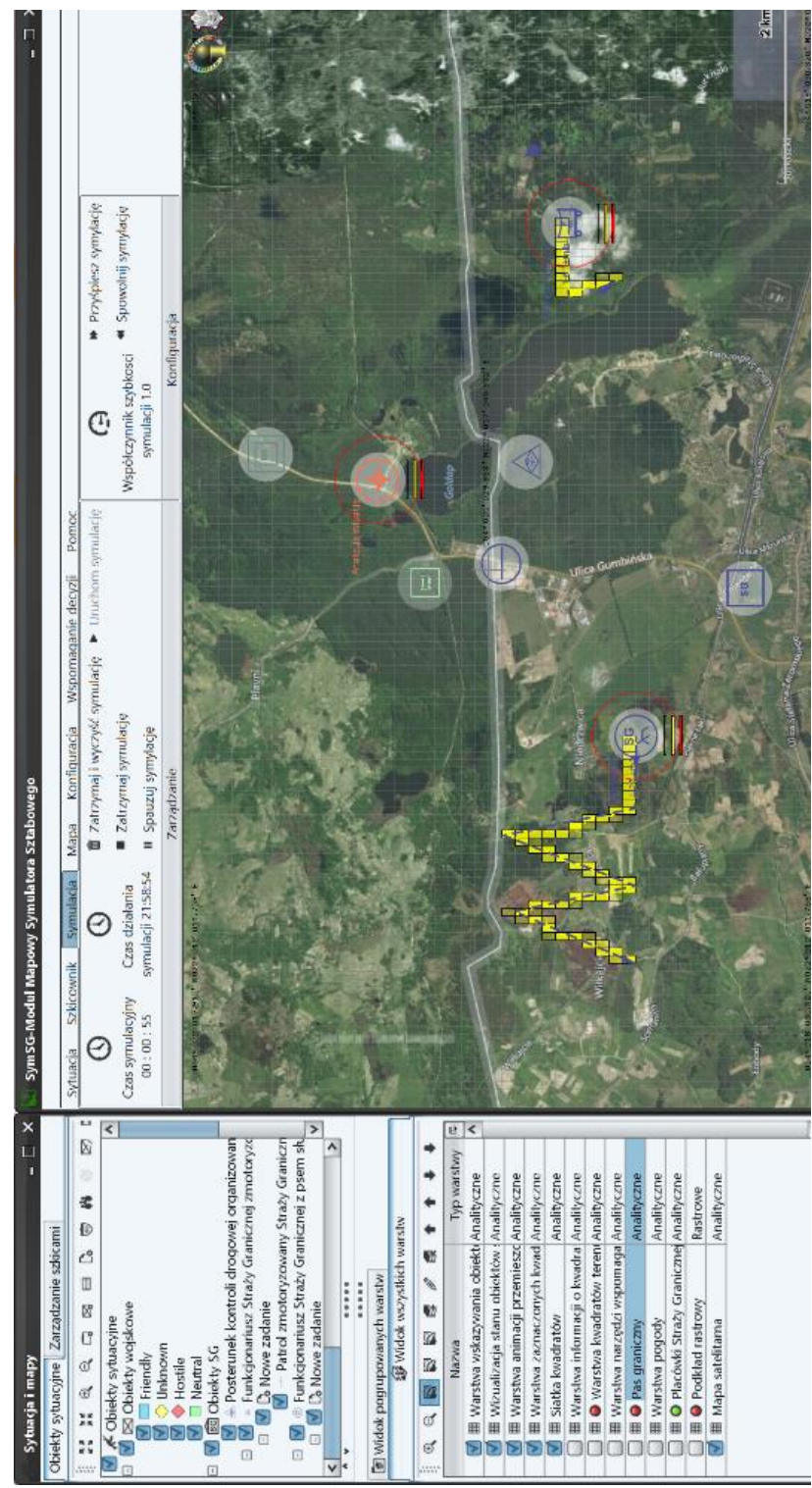

Fig. 10. Example of executing simulation exercise with active elements actions visualisation (routes) and data describing conducted tasks

The evaluation has been conducted during 30 minutes of simulation. Each scenario has been run 5 times in order to provide adequate results.

Table 3 Evaluation results of blockade elements simulation

\begin{tabular}{|l|c|c|}
\hline \multicolumn{1}{|c|}{ Element } & $\begin{array}{c}\text { Average time } \\
\text { of service [s] }\end{array}$ & $\begin{array}{c}\text { Average } \\
\text { traffic serviced }\end{array}$ \\
\hline Observation post & 6 & 300,00 \\
\hline Controlling post & 217 & 8,29 \\
\hline Blockade post & 97 & 18,56 \\
\hline Pursuit squad & 343 & 5,25 \\
\hline
\end{tabular}

Based on experience of Border Guard officers the results above show that the model reproduces the reality in good manner. The aim of simulation exercises is to allow students to work with unusual situations what is the case of higher probability of extraordinary issues like second line control or pursuit.

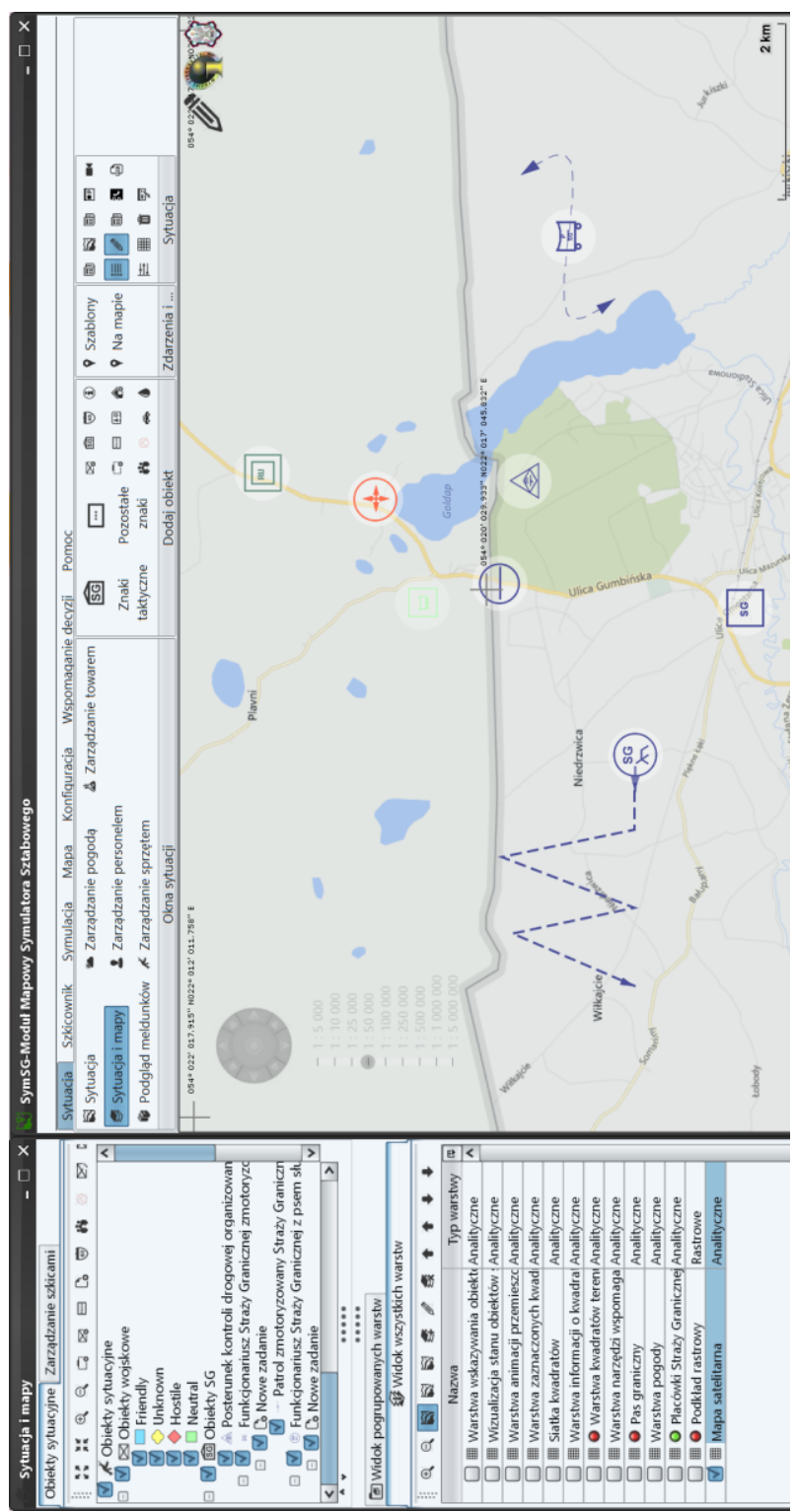

Fig. 11. Simulated scenario - initial situation prepared with initial set of elements with implemented decisions and prepared blockades

\section{Summary}

Presented in the paper method for modelling of aggregated simulation entities using queue models has proven to be a valid and valuable approach. It delivers configurability and provides parametrisation as well as calibration characteristics aligned with the operational data gathered by the border guards. Application support provided by the SymSG constructive simulator supplements the models with required operational 
element (border crossing, blockade, check point) design details. Implemented simulation models provide additional tuning features, which can be used to redesign border guard behavioural models, add new special events affecting the efficiency of designed que systems. Further research will be aimed at extending functionality of operational nodes by delivering declarative scripting engine which will equip the operational analyst with the tool to graphically reorganise behavioural models of nodes composing the que system.

Acknowledgements: this work has been supported by the National Centre for Research and Development grant DOBR/0023/R/ ID3/2013/03

\section{References}

1. Ministry of the Interior and Administration Decision No 13, Essential set of agreed symbology for operational and organisational units of the Ministry of Foreign Affairs Internal and Administration Departments and organisational units supervised by the Minister of the Interior and Administration, 28 January 2008.

2. Chmielewski, M. (2009). Ontology Applications for Achieving Situation Awareness in Military Decision Support Systems. In ICCCI 2009: Computational Collective Intelligence. Semantic Web, Social Networks and Multiagent Systems (pp. 528-539). Berlin : Springer.

3. Chmielewski M., Gałka A. (2010). Semantic Battlespace Data Mapping Using Tactical Symbology. Advances in Intelligent Information and Database Systems(DOI: 10.1007/978-3-642-120909 14), 157-168.

4. Knight P., Corder A., Liedel R., Giddens J., Drake R., Jenkins C., Agarwal P. (2015), "Evaluation of Run Time Infrastructure (RTI) Implementations", The Journal of Defense Modeling and Simulation: Applications, Methodology, Technology. Society for Modeling and Simulation International.

5. OpenMap framework website (access: 2017), http://openmap-java.org

6. Border Guard Training Centre, Kętrzyn, (access: 2018) website: http://www.cs.strazgraniczna.pl/

7. Ferg S., (2006) Event-Driven Programming: Introduction, Tutorial, History, http://Tutorial_EventDrivenProgramming.sourcefor ge.net,v. 0.2

8. Najgebauer A., Pierzchała D., Dyk M., (2015) AgentBased M\&S of Smart Sensors for Knowledge Acquisition Inside the Internet of Things and Sensor Networks, LNCS v.9012, ACIIDS pp 224-234

9. Chmielewski M., Stąpor P., Kędzior J., Kukiełka M., Methods and tools for generating high detail terrain model utilized in movement and behavioral models, reflecting border control actions, WSEAS Transactions on Environment and Development 13 (2017), 367
10. Chmielewski M., Frąszczak D., Kukiełka M., Bugajewski D., The Architectural Software Concepts Implemented in Distributed High Resolution Constructive Simulation Environment SymSG Border Tactics, Supporting Polish Border Guard Computer Assisted Exercises, Conference: 21st International Conference on Circuits, Systems, Communications and Computers (CSCC 2017), July 2017, Crete, Greece

11. Chmielewski M., Stąpor P., Kędzior J., Kukiełka M., High Detail Terrain Models and Multiresolution Path Finding Algorithms for Border Guard Constructive Simulator. A Study of Effective Movement Algorithms in High Resolution Simulation Environment, Conference: 21st International Conference on Circuits, Systems, Communications and Computers (CSCC 2017), 2017, Crete, Greece

12. Sundarapandian, V., Queueing Theory. Probability, Statistics and Queueing Theory. PHI Learning, (2009), ISBN 8120338448.

13. Reiser, M.; Lavenberg, S. S., Mean-Value Analysis of Closed Multichain Queuing Networks, Journal of the ACM. $27 \quad$ (2): $313, \quad 1980$, doi:10.1145/322186.322195.

14. Kelly, F. P., Networks of Queues with Customers of Different Types, Journal of Applied Probability, 12 (3): 542-554, JSTOR 3212869, 1975 